\title{
Hepatitis B surface antigen
}

\section{Role of lipids in maintaining the structural and antigenic properties of protein components}

\author{
Francisco GAVILANES, ${ }^{\S}$ Julian GOMEZ-GUTIERREZ,* Miguel ARACIL, ${ }^{*} \|$ Jose M. GONZALEZ-ROS, $\dagger$ \\ Jose A. FERRAGUT, $\dagger$ Eloisa GUERRERO $\ddagger$ and Darrell L. PETERSON $\ddagger$ \\ *Departamento de Bioquímica y Biología Molecular, Facultad de Ciencias, Universidad Complutense, 28040 Madrid, Spain, \\ †Departamento de Neuroquímica, Facultad de Medicina, Universidad de Alicante, Apdo. 99, Alicante, Spain, \\ and $\ddagger$ Department of Biochemistry, Medical College of Virginia (VCU), Box 614, MCV Station, Richmond, VA 23298, U.S.A.
}

\begin{abstract}
Most of the lipid components of hepatitis B surface antigen (HBsAg) can be removed by treatment with the non-ionic non-denaturing detergent $\beta$-D-octyl glucoside (OG) followed by centrifugation through caesium chloride linear density gradients (density $1.15-1.32 \mathrm{~g} / \mathrm{ml}$ ). The conformational changes induced by the elimination of lipids decreased the helical content of HBsAg proteins from 52 to $28 \%$ as indicated by c.d. techniques. Measurements of the extent of quenching of protein fluorescence by iodide showed that half of the tryptophan residues which are buried in the native structure of $\mathrm{HBsAg}$ particles are brought close to the surface of the molecule by such conformational changes. The antigenic activity, as measured by binding to polyclonal antibodies, was decreased upon removal of lipids. Moreover, the six different antigenic sites recognized by our panel of monoclonal antibodies decreased their capacity to bind to the corresponding antibody when lipids were removed. However, the extent of this decrease differed for the different antibodies. Thus the apparent dependence of antibody binding on the lipid content seemed to indicate a greater involvement of the lipid-protein interaction for some of the epitopes than for others.
\end{abstract}

\section{INTRODUCTION}

Hepatitis B surface antigen (HBsAg) is the envelope of the hepatitis B virus (HBV). During HBV infection, hepatocytes synthesize and secrete HBsAg to excess, mainly in the form of lipoprotein particles of $20 \mathrm{~nm}$ diameter which are observable by electron microscopy (Bayer et al., 1968; Almeida et al., 1969). HBsAg is a complex macromolecular aggregate with an $M_{\mathrm{r}}$ of $3.5 \times 10^{6}$ composed of protein ( $75 \%$ by weight), carbohydrates (in the form of glycoproteins) and host-derived lipids (25\%) (Gavilanes et al., 1982). SDS/polyacrylamide-gel electrophoresis of purified HBsAg reveals the existence of two proteins, designated S and $\mathrm{gS}$ (the glycosylated form of S), which account for more than $90 \%$ of the protein contained in HBsAg. These two proteins have been demonstrated to be the translation products of the same gene, with the only difference being the presence of the carbohydrates attached to gS at position Asn-146 (Peterson, 1981; Peterson et al., 1982).

Of the different components of $\mathrm{HBsAg}$, it is the proteins which are responsible for the induction of antibodies, and both the group- and subtype-specific antigenic determinants are localized within the proteins (Dreesman et al., 1975; Shih \& Gerin, 1975; Shih et al., 1978; Sanchez et al., 1981). However, it is highly probable that lipids exert some effect on the antigenic activity of $\mathrm{HBsAg}$, since the $\mathrm{HBsAg}$ proteins interact with the lipid components in the native particle. Regarding the role of the lipids in the antigenic activity of $\mathrm{HBsAg}$, controversial reports have appeared in the literature. Thus Kim \&
Bissell (1971) showed that HBsAg retained the antigenic activity after removal of the lipid and concluded that the lipid components were unrelated to the antigenicity. However, Goudeau et al. (1978) showed that treatment of $\mathrm{HBsAg}$ with deoxycholate markedly increased the antigenic titre of their preparations. Skelly et al. (1981) reported that $\mathrm{HBsAg}$ micelles obtained after treatment with $2 \%$ Triton X-100 were devoid of lipids, but were able to compete with intact $\mathrm{HBsAg}$, although the competitive ability of the micelles was only about $40 \%$ of that of the intact particles.

Regarding the possible role of lipids on immunogenicity, it has been reported that HBsAg proteins isolated from SDS/polyacrylamide gels under reducing conditions induce lower levels of antibodies than intact antigen (Sanchez et al., 1981, 1982, 1983). Although such proteins are devoid of lipid, it is not possible to assess whether delipidation or denaturation and reduction of disulphide bridges is mainly responsible for the poor immunogenicity. On the other hand, polypeptide micelles obtained upon removal of lipids with Triton X-100 have been reported to be more immunogenic than the intact particle (Skelly et al., 1981; Howard et al., 1982; Melnick et al., 1982; Sanchez et al., 1983; Zuckerman, 1984). Also, higher levels of antibodies were induced when HBsAg was incorporated into liposomes composed chiefly of egg phosphatidylcholine and cholesterol (Manesis et al., 1979). Moreover, the fact that proteins produced by cloning of HBV DNA, in both yeast and mammalian systems, spontaneously form lipoprotein particles with a diameter of about $20 \mathrm{~nm}$, indicates that

Abbreviations used: HBsAg, hepatitis B surface antigen; HBV, hepatitis B virus; OG, $\beta$-D-octyl glucoside.

$\|$ Present address: Antibióticos-Farma, C/Antonio Lopez, 109, 28026 Madrid, Spain.

$\S$ To whom correspondence should be addressed. 
lipid-protein interactions are necessary for the expression of the native structure (Charnay et al., 1980; Valenzuela et al., 1982; Hitzeman et al., 1983; Smith et al., 1983).

In an attempt to investigate further the possible role of lipids in maintaining the structure and antigenicity of HBsAg proteins, we describe here the properties of HBsAg from which a substantial amount of lipids has been removed by treatment with the non-denaturing detergent $\beta$-D-octyl glucoside (OG) followed by centrifugation through $\mathrm{CsCl}$ gradients. Iodide quenching and c.d. have been used as structural probes, and monoclonal antibodies (against both group- and subtype-specific determinants) have been employed as reporters of the antigenic activity.

\section{EXPERIMENTAL PROCEDURES}

\section{Materials}

OG was purchased from Calbiochem; electrophoresis reagents were obtained from Bio-Rad, and trypsin was obtained from Sigma. $\mathrm{CsCl}$ was from Aldrich, and solutions of $\mathrm{CsCl}$ were filtered through GSWP04750 Millipore filters before use. Ausria II-125 and Ausab kits used for measuring antigenic activity were purchased from Abbott Laboratories.

\section{Purification of HBsAg}

HBsAg was purified from the plasma of high-titre chronic carriers of $\mathrm{HBsAg}$, adw subtype, using previously described procedures (Peterson, 1981).

Protein concentration was determined either from the absorbance spectrum, using the value of 3.726 as the absorbance at $280 \mathrm{~nm}$ of a $0.1 \%$ solution of HBsAg in a cuvette of $1 \mathrm{~cm}$ path length (Vyas et al., 1972), or by amino acid analysis in which aliquots of protein $(10-$ $20 \mu \mathrm{g}$ ) were hydrolysed in sealed evacuated tubes with boiling $\mathrm{HCl}$ for $24 \mathrm{~h}$ at $110^{\circ} \mathrm{C}$. Amino acid analysis was performed with a Durrum D-500 amino acid analyser. Lipid phosphorus was determined by the micromethod of Barlett (1959) as previously described (Gavilanes et al., 1982).

\section{Removal of lipids}

HBsAg dissolved in $10 \mathrm{~mm}$-Tris/ $\mathrm{HCl}, \mathrm{pH} 7.0$, was incubated with the non-ionic detergent OG under the following conditions: $O G$ concentration, $0.5-3.75 \%$ $(\mathrm{w} / \mathrm{v})$; time, $2-18 \mathrm{~h}$, temperature, $10-40^{\circ} \mathrm{C}$; ionic strength, $0.01-0.5 \mathrm{M}-\mathrm{NaCl}$. In all cases, the final protein concentration was maintained at about $1 \mathrm{mg} / \mathrm{ml}$. HBsAg incubated with OG (or a control sample not treated with detergent) was layered on to a $12.8 \mathrm{ml} \mathrm{CsCl}$ linear gradient (density $1.15-1.32 \mathrm{~g} / \mathrm{ml}$ ), containing or lacking $0.16 \% \mathrm{OG}$, and was centrifuged for $4 \mathrm{~h}$ at $154400 \mathrm{~g}$ in a Beckman SW40 rotor. The position of HBsAg did not change on increasing the centrifugation time. Fractions of $0.4 \mathrm{ml}$ were collected beginning from the bottom of the gradient, and absorbance at $280 \mathrm{~nm}$ was determined for each fraction. Antigen-positive fractions, as judged by reaction with polyclonal antibodies, were pooled and dialysed against $10 \mathrm{~mm}$-Tris ( $\mathrm{pH} \mathrm{7.0)/50} \mathrm{mM-}$ $\mathrm{NaCl}$.

\section{Fluorescence measurements}

Fluorescence studies were carried out with a PerkinElmer MPF-44E spectrofluorimeter fitted with a $150 \mathrm{~W}$ xenon arc and a differential correction spectra unit
(DCSU-2). The temperature in the cuvette was maintained by a Lauda circulating water bath. Quenching was performed by adding aliquots of a stock solution of $2 \mathrm{M}$ $\mathrm{KI}$, containing $0.1 \mathrm{mM}-\mathrm{Na}_{2} \mathrm{~S}_{2} \mathrm{O}_{3}$ to prevent $\mathrm{I}_{3}{ }^{-}$formation, to a solution of $\mathrm{HBsAg}(5.5-20 \mu \mathrm{g} / \mathrm{ml})$. Emission spectra, for an excitation wavelength of $290 \mathrm{~nm}$, were recorded for each quencher concentration. Fluorescence intensities at the emission maximum $(333 \mathrm{~nm})$ were used for calculations. The higher quantum yield of Trp relative to Tyr together with the wavelength chosen means that the observed fluorescence was due mainly to Trp residues. The analysis of quenching was performed according to a modified form of the Stern-Volmer relationship:

$$
F_{0} /\left(F_{0}-F\right)=1 /\left([\mathrm{Q}] f_{\mathrm{a}} K_{\mathrm{a}}\right)+1 / f_{\mathrm{a}}
$$

where $F_{0}$ is the fluorescence in the absence of quencher, $F$ is the fluorescence at a molar quencher concentration $[\mathrm{Q}], K_{\mathrm{a}}$ is the Stern-Volmer quenching constant and $f_{\mathrm{a}}$ is the fraction of fluorescence accessible to the quenching agent (Lehrer, 1971). From a plot of $F_{0} /\left(F_{0}-F\right)$ versus $[\mathrm{Q}]^{-1}$, the values of $f_{\mathrm{a}}$ and $K_{\mathrm{a}}$ can be calculated. At each quencher concentration, $F_{0}$ was determined from a HBsAg solution to which aliquots of $2 \mathrm{M}-\mathrm{NaCl}$ were added. This allows for the correction of the protein fluorescence for any changes due to either dilution or the increase in ionic strength.

\section{Circular dichroism studies}

C.d. spectra were obtained on a Jobin Yvon Mark III dichrograph using a $0.1 \mathrm{~cm}$ path-length quartz cell and 60-120 $\mu \mathrm{g}$ of protein $/ \mathrm{ml}$. For every sample a minimum of three scans were collected. The values of mean residue $M_{\mathrm{r}}$ ellipticities were calculated on the basis of 110 as the average $M_{\mathrm{r}}$ per residue and they are reported in terms of $[\theta]_{\text {m.r.w. }}\left(\right.$ degrees $\cdot \mathrm{cm}^{2} \cdot \mathrm{dmol}^{-1}$ ). The secondary structure estimations were performed by computer fit according to the ellipticity reference values of Bolotina et al. (1980), which are based on proteins of known three-dimensional structure. The fitting is accomplished by the analytical method based on matrix formulation previously described (Menendez-Arias et al., 1988).

\section{Trypsin digestion}

HBsAg was digested with trypsin in $10 \mathrm{~mm}$-Tris (pH 7.0)/50 mM-NaCl, at a protein/trypsin ratio of 50:1 as described previously (Peterson, 1981).

\section{Polyacrylamide-gel electrophoresis}

Analytical polyacrylamide-gel electrophoresis was performed with a Bio-Rad Mini Protean II apparatus with a 7-25\% linear gradient polyacrylamide slab gel. A $4 \%$ stacking gel was used. The gel and buffer formulations were those of O'Farrel (1975). Gels were stained according to the silver nitrate staining method described by Merril et al. (1981).

\section{Antigenic activity assays}

The antigenic activity of HBsAg was determined using the Ausria II-125 kit from Abbott Laboratories. This is a 'sandwich' solid-phase radioimmunoassay which uses polyclonal (guinea pig) anti-HBsAg antibodies coated on to beads to capture any antigen in a sample incubated with the beads. Any bound antigen is then detected by incubating the beads with ${ }^{125}$ I-labelled polyclonal (human) anti-HBsAg antibody. The incubation conditions were those recommended by the manufacturers. 
After the final washing, the radioactivity bound to the beads was determined by using a Beckman Gamma 5500 counter. All the assays were done in duplicate.

Antigenic activity was also determined by using monoclonal antibodies and an inhibition radioimmunoassay based on the standard Ausab kit from Abbott Laboratories, modified as follows. A fixed amount of each monoclonal antibody was mixed with $\mathrm{HBsAg}$, either native or treated with OG, prepared in normal human serum, as well as with a control lacking antigen. Three HBsAg concentrations $(500 \mathrm{ng} / \mathrm{ml}, 50 \mathrm{ng} / \mathrm{ml}$ and $5 \mathrm{ng} /$ $\mathrm{ml}$ ) were used for each monoclonal antibody tested. After incubation for $2 \mathrm{~h}$ at room temperature, an Ausab bead (coated with $\mathrm{HBsAg}$ ) was added to each sample and incubated for $18 \mathrm{~h}$ at room temperature. Thus the monoclonal antibody which has not reacted with $\mathrm{HBsAg}$ in the initial mixture will bind to the bead. The amount of monoclonal antibody bound to the beads is then detected by incubation with ${ }^{125}$ I-labelled HBsAg. After the final washing, the radioactivity was determined as indicated above. The results are expressed as the percentage inhibition by the corresponding HBsAg of the ability of the monoclonal antibody to bind to HBsAgcoated beads, using the expression (Hoofnagle et al., 1977):

Inhibition $(\%)=$

$$
\frac{(\mathrm{MC} \text { anti-HBs }+\mathrm{NHS})-(\mathrm{MC} \text { anti-HBs }+\mathrm{HBsAg})}{\text { (MC anti-HBs + NHS) }- \text { (assay negative control) }}
$$

where (MC anti-HBs + NHS) is the radioactivity bound when the monoclonal is incubated with NHS alone, (MC anti-HBs + HBsAg) is that obtained when the monoclonal antibody is preincubated with $\mathrm{HBsAg}$ and the negative control gives the amount of ${ }^{125}$ I-labelled antigen which binds non-specifically to the beads, in an assay which lacks both the monoclonal and HBsAg. All assays were done in duplicate. Monoclonal antibodies were prepared and characterized as described previously (Peterson et al., 1984). The six monoclonal antibodies are all directed against the HBsAg protein and have the following specificities: $\mathrm{H} 35 \mathrm{C} 16, \mathrm{H} 5 \mathrm{C} 14$ and $\mathrm{H} 166 \mathrm{C} 63$ are directed against the group-specific 'a' determinant but not against the same site, since they do not compete with each other; H95C46 has the ' $d$ ' specificity, and H12C237 and $\mathrm{H} 53 \mathrm{C} 160$ cannot be assigned to determinants classifiable by their reactions against the accepted National Institutes of Health panel of subtypes (Peterson et al., 1984).

\section{RESULTS}

\section{Removal of lipids}

The removal of lipids from HBsAg was carried out by incubating the antigen with the non-ionic non-denaturing detergent $\mathrm{OG}$ followed by centrifugation through $\mathrm{CsCl}$ linear gradients. Other detergents, such as the ionic cholate or deoxycholate, had no effect on HBsAg density (results not shown), which suggests that no lipids are removed by these agents. Incubation of $\mathrm{HBsAg}$ with $\mathrm{OG}$ was routinely performed in $10 \mathrm{~mm}-$ Tris $(\mathrm{pH} 7.0) / 50 \mathrm{mM}-$ $\mathrm{NaCl}$ at room temperature for $2 \mathrm{~h}$; changing the incubation conditions did not alter significantly the extent of removal of lipids. The range of effective OG concentrations was between 1 and $2 \%(w / v)$. When HBsAg was incubated with $0.5 \%$ OG or less, both the density and the lipid/protein ratio of the particle were unaffected by

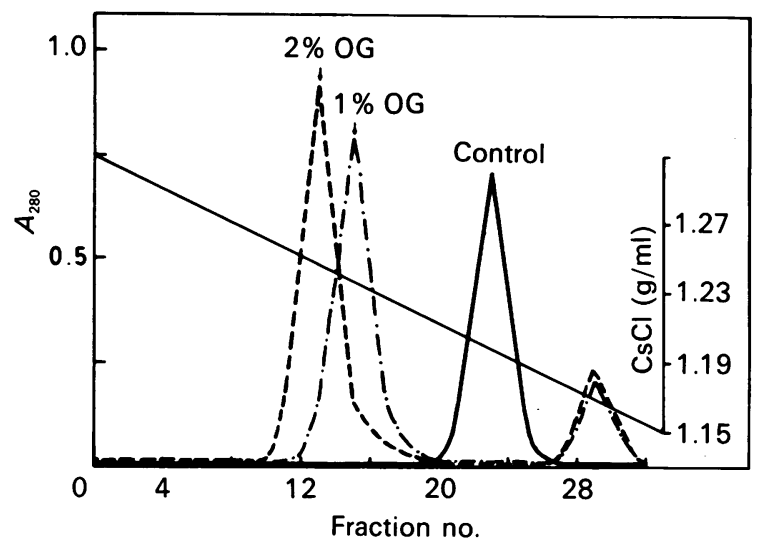

Fig. 1. Centrifugation of $\mathrm{HBsAg}$ on $\mathrm{CsCl}$ linear gradient

$\mathrm{HBsAg}(0.5 \mathrm{ml})$ in $10 \mathrm{~mm}-\mathrm{Tris}(\mathrm{pH} 7.0) / 50 \mathrm{~mm}-\mathrm{NaCl}$, containing approx. $0.5 \mathrm{mg}$ of protein, was incubated at room temperature for $2 \mathrm{~h}$ with $1 \%(-\cdot-\cdot-)$ or $2 \%(---)$ OG. A control sample (-) was incubated under the same conditions, but in the absence of OG. In every case, after centrifugation for $4 \mathrm{~h}$ at $35,000 \mathrm{rev} . / \mathrm{min}$, fractions of $0.4 \mathrm{ml}$ were collected beginning from the bottom of the tube. The density of the $\mathrm{CsCl}$ gradient was $1.15-1.32 \mathrm{~g} / \mathrm{ml}$ (straight line).

the treatment. At the other extreme, when the OG concentration was higher than $2 \%$, the antigen was recovered as an insoluble precipitate at the bottom of the gradient.

The density of native $\mathrm{HBsAg}(1.21 \mathrm{~g} / \mathrm{ml})$ increased upon treatment with $O G$ to a value of $1.23-1.24$ or $1.25-1.26 \mathrm{~g} / \mathrm{ml}$ for $1 \%$ and $2 \%$ OG respectively (Fig. 1). This increase is consistent with removal of lipids. Although when $\mathrm{HBsAg}$ was incubated with $\mathrm{OG}, 70-85 \%$ of the protein appeared at the density indicated above, an additional second band with a density lower than that of the native particle was observed at the top of the gradient.

The inclusion of $0.16 \%$ OG in the gradient did not change the yield or the density of the different bands. On the other hand, the maintenance of disulphide bridges was crucial for the removal of lipids while leaving the antigen proteins in a soluble, non-denatured form, since inclusion of $1 \mathrm{~mm}$-dithiothreitol during incubation with OG caused the antigen to precipitate, and when such an antigen was centrifuged, all the protein appeared at the bottom of the gradient.

Table 1. Lipid phosphorus content of HBsAg aster removal of lipids

The values indicated are means \pm S.D. for five different preparations. Total phosphorus was determined by the method of Barlett (1959); protein was determined by amino acid analysis as described in the Experimental procedures section.

Lipid/protein (ng of lipid phosphorus $/ \mu \mathrm{g}$ of protein)

Control

$1 \%$-OG-treated

$2 \%$-OG-treated

Low-density band
$11.5 \pm 0.5$

$5.0 \pm 1.0$

$3.5 \pm 0.5$

$20.0 \pm 4.0$ 


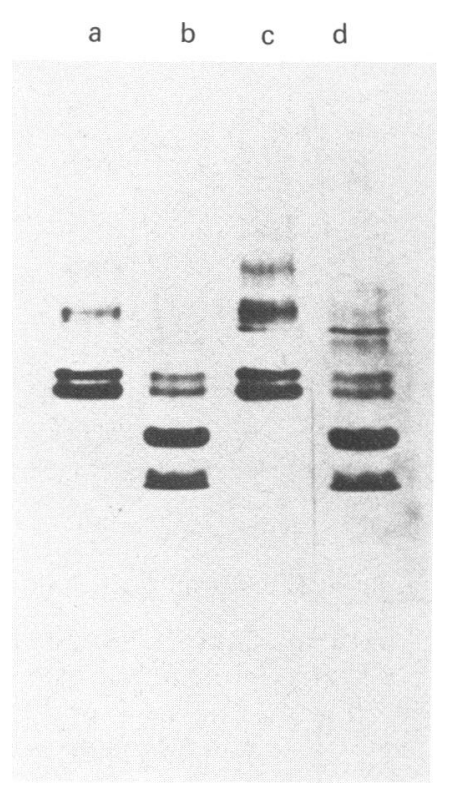

Fig. 2. SDS/polyacrylamide-gel electrophoresis of HBsAg treated with trypsin

A $1 \mu \mathrm{g}$ of portion of either HBsAg control (lanes a and b) or $\mathrm{HBsAg}$ treated with $2 \%$ OG to remove $70 \%$ of the lipid components (lanes c and d) was electrophoresed on a $0.75 \mathrm{~mm}$ thick $7-25 \%$ linear gradient polyacrylamide gel as described in the Experimental procedures section. The gel was stained with silver nitrate. Lanes a and $c$ show undigested samples, and lanes $b$ and $d$ show samples digested with trypsin for $4 \mathrm{~h}$.

Since phospholipids account for almost $70 \%$ of HBsAg lipids, the extent of lipid removal has been monitored by lipid phosphorus determination. No attempts have been made to measure other lipid classes. As shown in Table 1, treatment with $1 \%$ or $2 \%$ OG decreased the lipid content of $\mathrm{HBsAg}$ to $43 \%$ or $30 \%$ of the control respectively. Also, the lipid/protein ratio of the low-density migrating HBsAg was almost double that of the control.

SDS/polyacrylamide-gel electrophoresis showed clearly that $O G$ treatment followed by centrifugation through $\mathrm{CsCl}$ gradients had no effect on the overall protein content, as indicated by the ratio of $\mathrm{S}$ to $\mathrm{gS}$ proteins (approx. 2:1) (Fig. 2, lanes a and c). Negative staining electron microscopy reveals that $\mathrm{HBsAg}$ devoid of most lipids still maintains its particulated form (results not shown).

\section{Structural properties of HBsAg after removal of lipids}

Iodide quenching of protein fluorescence gives information on the different degrees of exposure of fluorophores. As a dynamic quencher, iodide exerts its action through collision with the fluorophore (Lehrer, 1971; Eftink \& Ghiron, 1976). Thus any change in quenching properties will reflect a variation in accessibility to the water-soluble quenching agent, which might include the occurrence of a conformational change. Moreover, since iodide is charged and highly hydrated, it will only interact with those fluorophores at or near the surface of the particle (Lehrer, 1971).

Stern-Volmer plots of quenching of HBsAg fluorescence by iodide, for both untreated samples and those

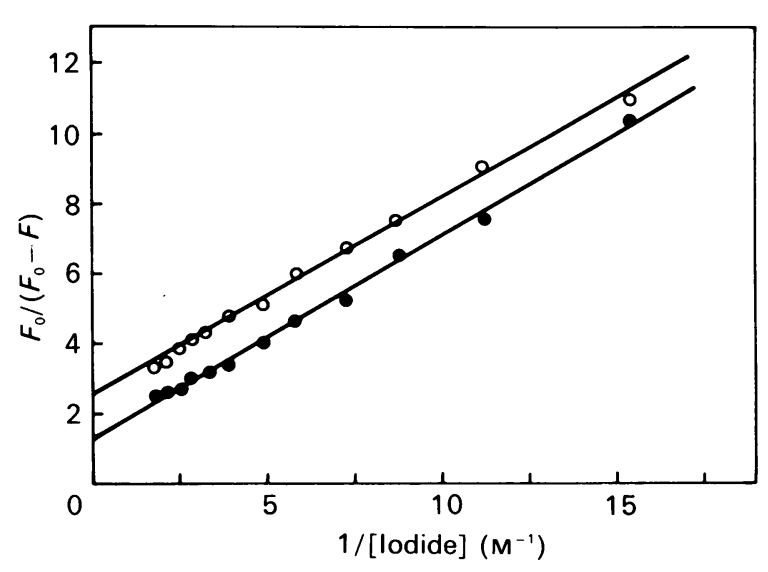

Fig. 3. Modified Stern-Volmer plot $\left\{\boldsymbol{F}_{0} /\left(\boldsymbol{F}_{0}-\boldsymbol{F}\right)\right.$ versus [iodide $\left.{ }^{-1}\right\}$ of $\mathrm{HBsAg}$ control $(O)$ and $\mathrm{HBsAg}$ treated with $2 \%$ OG (O)

From the fluorescence spectra of $\mathrm{HBsAg}$, at $5.5-20 \mu \mathrm{g} / \mathrm{ml}$ in $10 \mathrm{~mm}$-Tris $(\mathrm{pH} 7.0) / 50 \mathrm{~mm}-\mathrm{NaCl}$, for excitation at $290 \mathrm{~nm}$, the values of $F$, fluorescence at $333 \mathrm{~nm}$, were obtained. The value of $F_{0}$ was determined for a control sample to which $\mathrm{NaCl}$ was added (see the Experimental procedures section).

which had been treated with $2 \%$ OG, were non-linear, with a marked downward curvature (results not shown). This indicates (1) that at $0.55 \mathrm{M}$-iodide the protein is not denatured [an abrupt upward curvature would be observed if this were the case (Eftink \& Ghiron, 1976)], and (2) that there are two populations of Trp residues: accessible and inaccessible to iodide. Moreover, the population of fluorophores accessible to quencher is homogeneous, since when quenching of $\mathrm{HBsAg}$ fluorescence data are plotted according to the modified SternVolmer relationship, a linear plot is obtained (Fig. 3) (Lehrer, 1971). From this plot, the fluorescence parameters shown in Table 2 were obtained. The value of $f_{\mathrm{a}}=0.42$ for the control sample indicates that less than half of the Trp residues were accessible to iodide and therefore should be confined at or near to the surface of the particle, the remaining Trp being buried into the protein structure. The value of $f_{\mathrm{a}}=0.76$ for $\mathrm{HBsAg}$ treated with $2 \%$ OG indicates that $50 \%$ of the previously inaccessible Trp residues became accessible to the quenching agent upon removal of lipids. The low value of $K_{\mathrm{a}}, 4.8 \mathrm{M}^{-1}$, for the control sample indicated that the accessible $\operatorname{Trp}$ residues are not at the surface since $K_{\mathrm{a}}$ would otherwise be higher $\left[K_{\mathrm{a}}\right.$ for free $N$-acetyl-Ltryptophanamide in aqueous solution is $17.5 \mathrm{~m}^{-1}$ (Lehrer, 1971)]. Besides, when lipids were removed, $K_{\mathrm{a}}$ decreased

Table 2. Fluorescence parameters of iodide quenching

The values are means \pm S.D. for four different preparations.

\begin{tabular}{lcc}
\hline & $f_{\mathrm{a}}{ }^{*}$ & $K_{\mathrm{a}}{ }^{\dagger}\left(\mathrm{M}^{-1}\right)$ \\
\hline Control & $0.42 \pm 0.04$ & $4.8 \pm 0.6$ \\
$2 \%$-OG-treated & $0.76 \pm 0.14$ & $2.5 \pm 0.7$
\end{tabular}

* Fraction of fluorescence accessible to quencher.

$\dagger$ Quenching constant of accessible fluorescence. 


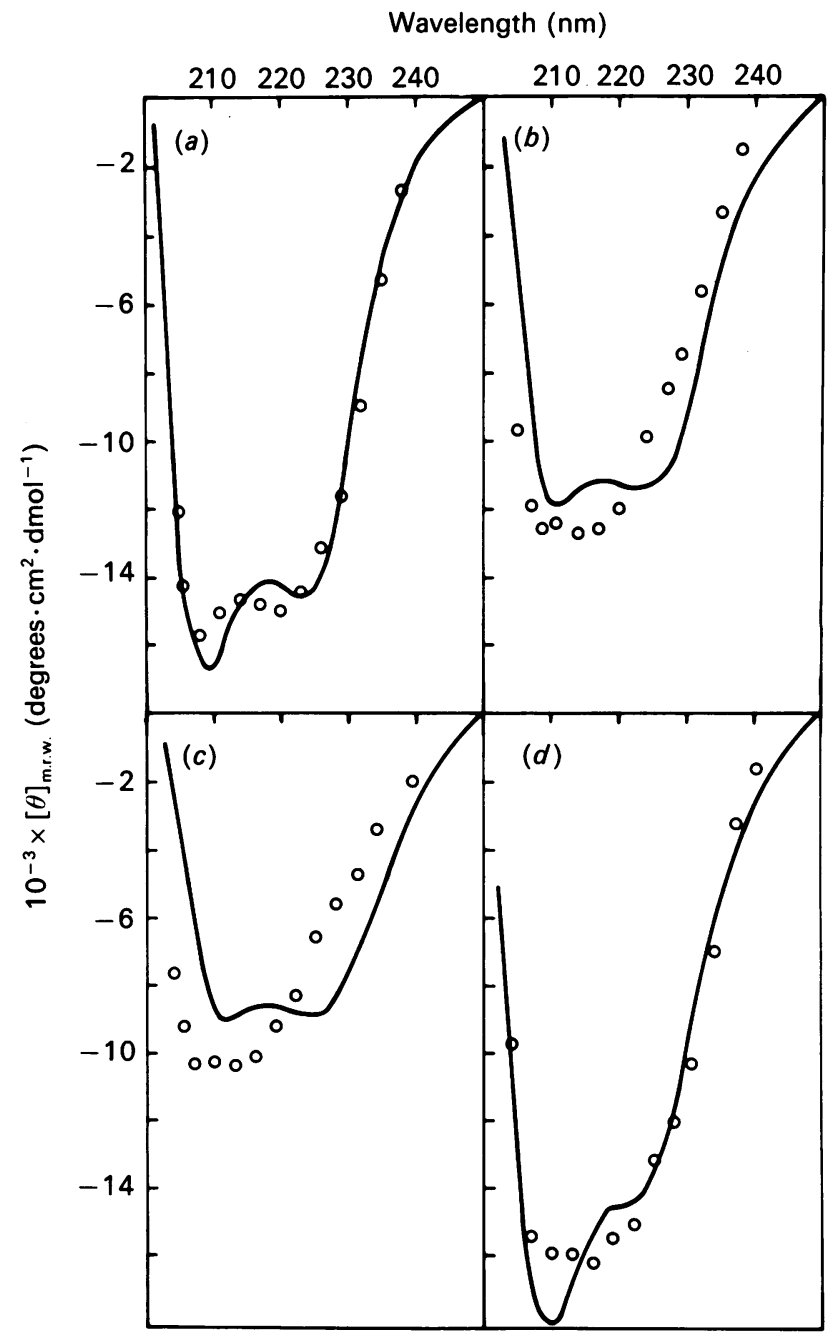

Fig. 4. Effect of lipid removal on c.d. spectrum of $\mathrm{HBsAg}$

(a) Native sample; (b) and (c) show the spectra of $\mathrm{HBsAg}$ centrifuged after incubation with $1 \%$ and $2 \%$ OG respectively; $(d)$ shows the spectrum of the low-density band which appeared at the top of the gradient when antigen is treated with OG. The protein concentration was $60-120 \mu \mathrm{g} / \mathrm{ml}$. Circles represent theoretical values calculated using the c.d. parameters of Bolotina et al. (1980) with the percentages of secondary structure given in Table 3.

to $2.5 \mathrm{M}^{-1}$, indicating that although there are more $\operatorname{Trp}$ residues accessible to the quenching agent, it is more difficult to quench their fluorescence than in native HBsAg. Similar behaviour has been reported for lysozyme, with $f_{\mathrm{a}}=0.38$ and $K_{\mathrm{a}}=7.0 \mathrm{M}^{-1}$ for the native state, whereas in the presence of guanidine hydrochloride these values are 1.0 and $2.1 \mathrm{M}^{-1}$ respectively (Lehrer, 1971). Values of $f_{\mathrm{a}}$ and $K_{\mathrm{a}}$ for the low-density migrating HBsAg were the same as those of the control, whereas those obtained for HBsAg treated with $1 \%$ OG were intermediate between those of the control and of $\mathrm{HBsAg}$ treated with $2 \%$ OG (results not shown). OG by itself did not induce any change in accessibility to the quenching agent, since $f_{\mathrm{a}}$ and $K_{\mathrm{a}}$ values for native $\mathrm{HBsAg}$ in the presence of OG (up to $2 \%$ ) but not subjected to $\mathrm{CsCl}$ gradient centrifugation, were very close to those obtained for the control sample.
Table 3. Secondary structure of HBsAg calculated from c.d. spectra

The values were calculated using the parameters of Bolotina et al. (1980), and are means \pm S.D. for four different preparations.

\begin{tabular}{llllc}
\hline & \multicolumn{4}{c}{ Conformation (\% of total) } \\
\cline { 2 - 5 } & $\alpha$-Helix & $\beta$-Sheet & $\beta$-Turn & $\begin{array}{c}\text { Aper- } \\
\text { iodic }\end{array}$ \\
\hline Control & $52 \pm 7$ & $15 \pm 6$ & $21 \pm 1$ & $13 \pm 7$ \\
$1 \%$ OG-treated & $35 \pm 5$ & $15 \pm 6$ & $19 \pm 5$ & $31 \pm 12$ \\
$2 \%$ OG-treated & $28 \pm 4$ & $19 \pm 5$ & $20 \pm 3$ & $32 \pm 9$ \\
$\begin{array}{l}\text { Low-density } \\
\text { band }\end{array}$ & $56 \pm 1$ & $12 \pm 4$ & $24 \pm 2$ & $8 \pm 6$ \\
\hline
\end{tabular}

C.d. spectra of HBsAg, both native and treated with $1 \%$ or $2 \%$ OG followed by centrifugation through $\mathrm{CsCl}$, are shown in Fig. 4. Both the form and magnitude of the spectrum changed considerably when the lipid content was diminished. Also, the c.d. spectrum of the low-density migrating $\mathrm{HBsAg}$ is different from that of native antigen (Fig. 4d).

The c.d. spectra of the different samples, both control and OG-treated, did not vary with the path-length or concentration. This precludes the occurrence of spectral changes due to the slight increase of scattering caused by the removal of lipids. Moreover, the observed changes are due to the elimination of the lipid component and not to the presence of detergent, since the c.d. spectrum of HBsAg did not change significantly when measured in the presence of $O G$ at concentrations up to $2.4 \%$ (results not shown).

As a measure of the change induced by the removal of the lipids, the protein secondary structure was calculated from the c.d. spectra according to the method previously described (Menendez-Arias et al., 1988), based on the parameters of Bolotina et al. (1980) (Table 3). The helical content of native $\mathrm{HBsAg}$ decreased from $52 \%$ to $35 \%$ and $28 \%$ when the antigen was treated with $1 \%$ and $2 \%$ OG respectively and centrifuged through the gradient. The calculated secondary structure of the low-density migrating HBsAg was almost identical with that of the control, in spite of the observed differences in the c.d. spectra and the lipid/protein ratio. The method used for calculation imposes the restriction that the sum of the frequencies for each estimated conformation $\left(\Sigma f_{\mathrm{i}}\right)$ is equal to 1 . However, when an iterative method is used, without constraint on the value of $\Sigma f_{i}\left(0.9<\Sigma f_{i}<1.1\right)$, essentially the same results are obtained, especially with regard to the helical content.

Hydrolysis by trypsin has also been used to examine the structural changes promoted by removal of $70 \%$ of the lipids, to see if additional trypsin-sensitive sites have been generated. Fig. 2 shows the results of trypsin digestion of untreated HBsAg (lanes a and b) and of HBsAg following treatment with $2 \%$ OG (lanes c and d). Trypsin digestion of $\mathrm{HBsAg}$ in the presence of $\beta$ mercaptoethanol has been shown previously to give rise to two fragments due to the hydrolysis of the peptide bond of Lys-22, which is at an exposed region in the intact particle (Peterson et al., 1982). The polypeptide pattern observed after digestion is not modified when the 


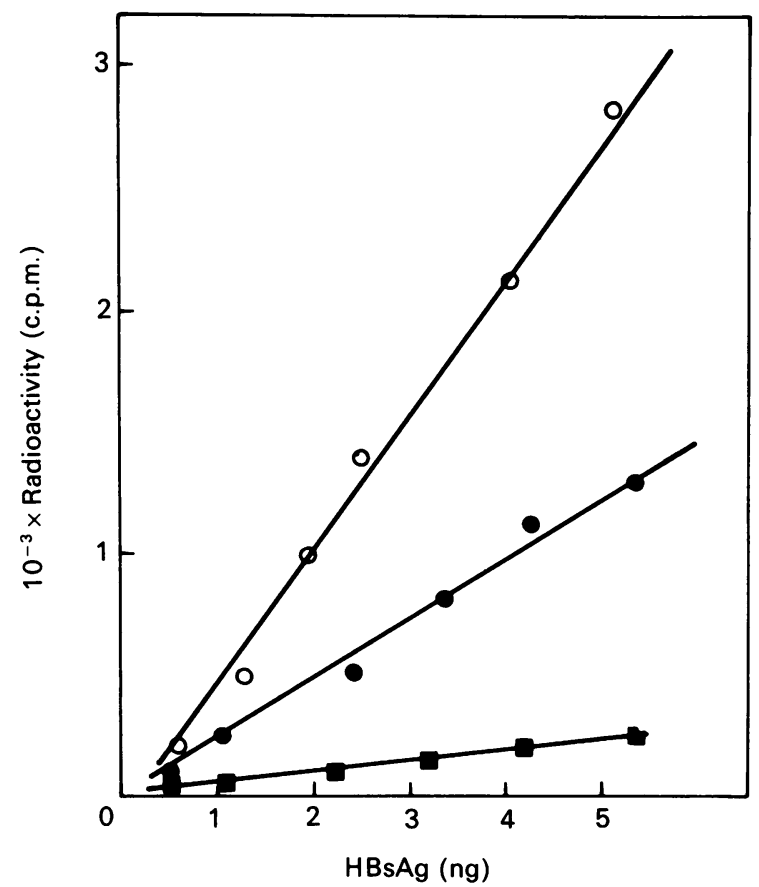

Fig. 5. Antigenic activity of $\mathrm{HBsAg}$

Control (O) antigens or devoid of lipids after treatment with $1 \%(O), 2 \%(\square) O G(0.5-5 \mathrm{ng})$ were incubated with beads coated with guinea pig anti-HBs antibodies. The antigen-antibody complex was then allowed to react with human ${ }^{125} \mathrm{I}$-anti-HBs antibodies. Radioactivity bound to the solid phase is shown versus the amount of $\mathrm{HBsAg}$ present in the assay.

lipid content is diminished. No additional peptides were observed (Fig. 2).

\section{Antigenic activity of HBsAg devoid of lipids}

As indicated in Fig. 5, the removal of $70 \%$ of the lipids from $\mathrm{HBsAg}$ caused a drastic decrease in antigenic activity as measured by guinea pig polyclonal anti-HBs antibodies. After treatment with 1 or $2 \% \mathrm{OG}, \mathrm{HBsAg}$ contained only $40-60 \%$ and $5-15 \%$ respectively of the antigenic activity of the control. HBsAg samples which were centrifuged through $\mathrm{CsCl}$ gradients, even in the presence of $0.16 \% \mathrm{OG}$, had the same antigenic activity as untreated HBsAg. In order to determine whether the observed decrease in antigenic activity was due to a complete modification of one particular determinant or to partial modification of several, assays were performed using a panel of monoclonal antibodies which recognize either group- or subtype-specific determinants (Peterson et al., 1984). The results are summarized in Table 4. All of the antigenic determinants recognized by our monoclonal antibodies decreased their capacity to bind the corresponding antibody when lipids were removed. However, their sensitivities to lipid removal were different. Thus elimination of part of the lipids by treatment with $1 \%$ OG clearly affects the binding of monoclonal antibodies $\mathrm{H} 53, \mathrm{H} 5$ and $\mathrm{H} 12$. For example, the inhibition at $500 \mathrm{ng}$ of $\mathrm{HBsAg} / \mathrm{ml}$, in excess over the monoclonal antibody, decreased to almost $50-60 \%$ of the corresponding control (i.e. inhibition for $\mathrm{H} 53$ decreased from $88.8 \%$ to $41.5 \%$ at $500 \mathrm{ng} / \mathrm{ml}$ ). For the other monoclonals the effect could be observed only at a lower
Table 4. Effect of lipid removal on the antigenic activity of HBsAg

The values were obtained according to the method described in the Experimental procedures section, and are representative of those obtained for three different preparations.

\begin{tabular}{lrrrr}
\hline & & \multicolumn{3}{c}{ Inhibition by HBsAg (\%) } \\
\cline { 3 - 5 } $\begin{array}{l}\text { Monoclonal anti- } \\
\text { HB antibody/ } \\
\text { subtype }\end{array}$ & $\begin{array}{c}\text { HBsAg } \\
\text { (ng/ml) }\end{array}$ & $\begin{array}{c}\text { Con- } \\
\text { trol }\end{array}$ & $1 \%$ OG & $2 \%$ OG \\
\hline H35C16/a & & & & \\
& 500 & 98.6 & 98.1 & 89.0 \\
& 50 & 93.3 & 71.4 & 35.4 \\
H95C46/d & 5 & 36.5 & 20.4 & 1.8 \\
& 500 & 99.7 & 99.6 & 83.9 \\
& 50 & 78.7 & 52.8 & 15.3 \\
H166C63/a & 5 & 19.3 & 3.1 & 4.6 \\
& 500 & 100.0 & 80.9 & 14.4 \\
& 50 & 44.1 & 12.9 & 10.8 \\
H12C237/undefined & 5 & 6.4 & 7.2 & 5.2 \\
& 500 & 81.7 & 55.9 & 32.9 \\
H53C160/undefined & 50 & 13.9 & 4.8 & 6.7 \\
& 5 & 6.8 & 2.8 & 2.4 \\
H5C14/a & 500 & 88.8 & 41.5 & 31.9 \\
& 50 & 19.1 & 10.0 & 2.1 \\
& 5 & 0.0 & 0.0 & 0.0 \\
& 500 & 93.2 & 56.9 & 28.9 \\
& 50 & 12.1 & 0.0 & 7.2 \\
& 5 & 7.5 & 0.0 & 0.0 \\
\hline
\end{tabular}

HBsAg concentration $(50 \mathrm{ng} / \mathrm{ml})$. When most of the lipids were removed by treatment with $2 \%$ OG, $\mathrm{HBsAg}$ had a lower capacity to inhibit the binding of all of the monoclonal antibodies to native $\mathrm{HBsAg}$. This is especially apparent for $\mathrm{H} 166$, since $500 \mathrm{ng}$ of $2 \%$ OGtreated $\mathrm{HBsAg} / \mathrm{ml}$ only inhibited $14.4 \%$ of binding, whereas after treatment with $1 \%$ OG and the same $\mathrm{HBsAg}$ concentration in the assay, the inhibition was $80.9 \%$. The epitopes defined by $\mathrm{H} 35$ and $\mathrm{H} 95$ are the least affected by the delipidation.

\section{DISCUSSION}

Treatment with $O G$ followed by centrifugation through a $\mathrm{CsCl}$ gradient allows the removal of a substantial amount of lipid from HBsAg particles. The lipid/protein ratio indicated that $70 \%$ of the lipid components were eliminated by this treatment. The reported procedure renders $\mathrm{HBsAg}$ particles in a soluble state which is amenable to physical and immunochemical studies. Lower levels of lipids could not be obtained, since when HBsAg was incubated with OG at concentrations higher than $2 \%$ and then centrifuged on $\mathrm{CsCl}$ gradients, the protein precipitated and could not be resolubilized in aqueous buffers, preventing structural studies being performed. Removal of $70 \%$ of the lipids by treatment with the detergent did not modify the S/gS protein ratio (approximately 2:1), and therefore it had no effect on the overall protein content of $\mathrm{HBsAg}$ particles.

As well as the delipidated material observed on $\mathrm{CsCl}$ gradients, an HBsAg band appeared at the top of the gradient. The fact that it had a lower density than native 
HBsAg makes it likely that this low-density migrating HBsAg has extra lipids derived from the native antigen incorporated into the particle structure.

Structural studies carried out with HBsAg after treatment with $O G$ indicate the importance of the lipid moiety for the maintenance of the native conformation. The c.d. spectrum of native HBsAg indicates that $\alpha$-helix is the most abundant secondary structure, accounting for almost $50 \%$ of the structure of $\mathrm{HBsAg}$ proteins. This conclusion is also supported by Fourier-transformed infra-red spectral studies of $\mathrm{HBsAg}$ (Guerrero et al., 1988) which indicated a major contribution of helical structure. Removal of part of the lipid component results in conformational changes which decrease the helical content of native antigen by about $50 \%$. The final structure should be stabilized mainly through proteinprotein interactions involving hydrophobic regions and disulphide bridges, without the lipid-protein interactions that occur in the native particle. The hydrophilic region remains exposed to the solvent and no evidence of gross changes was observed, since there was no increase in the number of peptide bonds susceptible to hydrolysis by trypsin. Although lipid incorporation into the lowdensity migrating HBsAg changed both the lipid/protein ratio and the c.d. spectrum, the secondary structure determined by the method of Bolotina et al. (1980) was identical with that of untreated HBsAg.

HBsAg has 13 Trp residues. Based on sequence data and hydropathic scores, nine of these Trp residues are predicted to be located in the highly hydrophobic segment of the protein between residues 161 and 201 (see Fig. 4 in Hemling et al., 1988). The results of studies of the quenching of the protein fluorescence by iodide indicated that more than half of the Trp residues are inaccessible, and thus are buried in the native particle structure. Removal of the majority of the lipids resulted in conformational changes that exposed about $50 \%$ of these previously buried Trp residues. Thus it is likely that after delipidation, some of the Trp residues located in this hydrophobic region are those which become more accessible to iodide, and that this results from the conversion of this region from a helical lipid-associated region to an aperiodic structure not associated with lipid. The incorporation of additional lipids into the lowdensity band did not affect the iodide quenching pattern with respect to the native particle. This would be the expected result, since the buried Trp residues are already in an unexposed, lipid-associated, helical segment that would not be expected to be affected by the addition of extra lipids.

From the data described, one would tend to conclude that the conformational changes induced by removal of lipids only take place in the hydrophobic portion of HBsAg proteins. The trypsin hydrolysis data do not support the occurrence of any conformational change in the hydrophilic regions. However, since the antigenic activity (as measured by the binding of polyclonal antibodies) decreased upon removal of lipids, some changes in the conformation of the exposed regions must have occurred which perhaps do not affect peptide bonds amenable to trypsin proteolysis.

A similar decrease of antigenic activity has been described following treatment with Triton X-100 (Skelly et al., 1979, 1981). When HBsAg was treated with Triton $\mathrm{X}-100$ and the proteins purified by affinity chromatography, only $65 \%$ of the protein could be precipitated with anti-HBs antibodies (Skelly et al., 1979). The competitive ability of these proteins against native $\mathrm{HBsAg}$ was only $40 \%$ of that of the control (Skelly et al., 1981). On the other hand, it has been shown that proteins purified by this procedure induce higher levels of antibody production than does the commercially available vaccine Heptavax (Merck, Sharp and Dome, West Point, PA, U.S.A.) (Howard et al., 1982; Hollinger et al., 1986), which consists of the native lipoprotein particle. The higher immunogenicity of these preparations could be due to a different distribution of antigenic determinants on the surface of the particle (Skelly et al., 1981). This role for the lipids in maintaining the antigenicity and immunogenicity of HBsAg proteins contrasts with other results described previously (Kim \& Bissell, 1971; Goudeau et al., 1978). Thus Kim \& Bissell (1971) have reported that lipids are unrelated to the antigenicity, since after treatment with SDS and diethyl ether, $\mathrm{HBsAg}$ gave a precipitin line with antibodies on immunoelectrophoresis. However, their methods were not appropriate to quantify the antigenic activity, but rather were only qualitative, indicating that some antigenic activity remained. As shown here, HBsAg can still react with antibodies after removal of most of the lipid components, although to a lesser extent. On the other hand, it has been reported that treatment with deoxycholate increased the antigenic titre to $125 \%$ of the original by unmasking additional antigenic sites (Goudeau et al., 1978). In those studies, however, no lipid determinations were performed. Furthermore, our observations using cholate and other ionic detergents indicate that the density of HBsAg is not altered by this treatment, and thus it is likely that no lipids were removed from the particle in this case.

All of the antigenic determinants that react with our panel of monoclonal antibodies were affected by removal of the lipids and are thus partly dependent on the native conformation, although to different extents. The antigenic determinant recognized by the monoclonal antibody $\mathrm{H} 53$ is the most affected by removal of $55 \%$ of the lipids, whereas those epitopes defined by H35 and H95 are the least dependent on lipids, and only the more extensive conformational changes induced by removal of $70 \%$ of the lipids could modify binding to the corresponding antibodies. This could indicate differences in the proximity of the different antigenic determinants to the lipid-protein interface.

These results also provide an insight into the reason why $\mathrm{HBsAg}$ that is produced in a variety of hosts from cloned DNA is present in a particle that is antigenically nearly identical to the natural particle, even though the lipid components are not the same. The lipid-protein interactions are responsible for the formation of the proper helical structure of the protein, which disposes the remainder of the protein on the surface or interior of the particle. These interactions stabilize the conformation of the exterior hydrophilic regions which contain the antigenic sites. The fact that the major group-specific and subtype-specific determinants are among the least affected by alterations in the lipid is then consistent with the fact that changes in the lipid components due to differences in the host cell in which the HBsAg is made do not result in significant differences in these antigenic sites. Such effect of lipids can be assessed more fully by reconstitution experiments, in which defined lipids are incorporated into delipidated particles. 
This research was supported in part by Grant CCA8510/034 from the U.S.-Spain Joint Committee for Scientific and Technological Co-operation.

\section{REFERENCES}

Almeida, J. D., Zuckerman, A. J., Taylor, P. E. \& Waterson, A. P. (1969) Microbiology 1, 117-123

Barlett, G. R. (1959) J. Biol Chem. 234, 466-468

Bayer, M. E., Blumberg, B. S. \& Werner, B. (1968) Nature (London) 218, 1057-1059

Bolotina, I. A., Chekhov, V. O., Lugauscas, V. Y. \& Ptitsyn, O. B. (1980) Mol. Biol. (USSR) 14, 902-908

Charnay, P., Gervais, M., Louise, A., Galibert, F. \& Tiollais, P. (1980) Nature (London) 286, 893-895

Dreesman, G. R., Hollinger, F. B. \& Melnick, J. L. (1975) Am. J. Med. Sci. 270, 123-129

Eftink, M. R. \& Ghiron, C. A. (1976) Biochemistry 15, 672-680

Gavilanes, F., González-Ros, J. M. \& Peterson, D. L. (1982) J. Biol. Chem. 257, 7770-7777

Goudeau, A., Barin, G., Coursaget, P., Sizaret, P. Y., Andre, M. \& Maupas, P. (1978) in Viral Hepatitis (Vyas, G. N., Cohen, S. N. \& Schmid, R., eds.), pp. 707-708, Franklin Institute Press, Philadelphia

Guerrero, E., Gavilanes, F. \& Peterson, D. L. (1988) in Viral Hepatitis and Liver Disease (Zuckerman, A. J., ed.), pp. 606-613, Alan R. Liss, New York

Hemling, M. E., Carr, S. A., Capian, C. \& Petre, J. (1988) Biochemistry 27, 699-705

Hitzeman, M. R., Chen, C. Y., Hagie, F. E., Patzer, E. J., Liu, C. C., Estell, D. A., Miller, J. V., Yaffe, A., Kleid, D. G., Levinson, A. D. \& Opperman, H. (1983) Nucleic Acids Res. 11, 2745-2763

Hollinger, F. B., Troosi, C., Heiberg, D., Sanchez, Y., Dreesman, G. R. \& Melnick, J. L. (1986) J. Med. Virol. 19, 229-240

Hoofnagle, J. H., Gerety, R. J., Smallwood, L. A. \& Barker, L. F. (1977) Gastroenterology 72, 290-296

Howard, C. R., Skelly, J., Tsignaye, N., Zuckerman, A., Tabor, E., Gerety, R. \& Kremastinou, T. (1982) in Viral Hepatitis (Szmuness, A. M. \& Maynard, J. E., eds.), pp. 411-413, Franklin Institute Press, Philadelphia

Received 5 June 1989/18 September 1989; accepted 28 September 1989
Kim, C. Y. \& Bissell, D. M. (1971) J. Infect. Dis. 123, 470476

Lehrer, S. S. (1971) Biochemistry 10, 3254-3263

Manesis, E. K., Cameron, C. H. \& Gregoriadis, G. (1979) FEBS Lett. 102, 107-111

Melnick, J. L., Dreesman, G. R. \& Hollinger, F. B. (1982) Infect. Dis. 12, 8

Menendez-Arias, L., Gomez-Gutierrez, J., Garcia-Fernandez, M., Garcia-Tejedor, A. \& Moran, F. (1988) Comput. Appl. Biosci. 4, 479-482

Merril, C. R., Goldman, D., Sedman, S. A. \& Eber, M. M. (1981) Science 211, 1437-1438

O'Farrel, P. H. (1975) J. Biol. Chem. 250, 4007-4021

Peterson, D. L. (1981) J. Biol. Chem. 256, 6975-6985

Peterson, D. L., Nath, N. \& Gavilanes, F. (1982) J. Biol. Chem. 256, 10414-10420

Peterson, D. L., Paul., D. A., Lam, J., Tribby, I. I. E. \& Achord, D. T. (1984) J. Immunol. 132, 920-927

Sanchez, Y., Ionescu-Matiu, I., Dreesman, D. R., Hollinger, F. B. \& Melnick, J. L. (1981) Virology 114, 71-80

Sanchez, Y., Ionescu-Matiu, I., Sparrow, J. T., Melnick, J. L. \& Dreesman, G. R. (1982) Intervirology 18, 209213

Sanchez, Y., Ionescu-Matiu, I., Melnick, J. L. \& Dreesman, G. R. (1983) J. Med. Virol 11, 115-124

Shih, J. W. K. \& Gerin, J. L. (1975) J. Immunol. 115, 634 639

Shih, J. W. K., Tan, P. L. \& Gerin, J. L. (1978) J. Immunol. 120, 520-525

Skelly, J., Howard, C. R. \& Zuckerman, A. R. (1979) J. Gen. Virol. 44, 679-689

Skelly, J., Howard, C. R. \& Zuckerman, A. J. (1981) Nature (London) 290, 51-54

Smith, G. L., McKett, M. \& Moss, B. (1983) Nature (London) 302, 490-495

Valenzuela, P., Medina, A., Rutter, W. J., Ammerer, G. \& Hall, B. D. (1982) Nature (London) 298, 347-350

Vyas, G. N., Williams, E. W., Klaus, G. G. B. \& Bond, H. E. (1972) J. Immunol. 108, 1114-1118

Zuckerman, A. J. (1984) in Advances in Hepatitis Research (Chisari, F. J., ed.), pp. 230-237, Masson Publishing, New York 